\title{
Staphylococcus aureus Biofilms and their Impact on the Medical Field
}

\author{
Fany Reffuveille, Jérôme Josse, Quentin Vallé, \\ Céline Mongaret and Sophie C. Gangloff \\ Additional information is available at the end of the chapter
}

http://dx.doi.org/10.5772/66380

\begin{abstract}
Despite the discovery of antibiotics, the battle against bacteria is so far in their favor, specifically because bugs are able to develop a superstructure named biofilm, to resist and to survive in the environment. Nosocomial infections, a major health problem, are due at $80 \%$ to biofilm-associated infection, and Staphylococcus aureus is the leading bacteria species in this domain. Moreover, the antimicrobial resistance of this bacterial community is accentuated when it is formed by superbugs such as methicillin-resistant $S$. aureus (MRSA). In this chapter, the mechanism and the physiology of S. aureus biofilm as well as their consequences in the clinical domains are described. To complete the vision on $S$. aureus biofilms, some "anti-biofilm" strategies will be highlighted.
\end{abstract}

Keywords: Staphylococcus aureus, biofilm, antibiotic resistance, anti-biofilm strategies

\section{Introduction}

Discoveries in microbiology and the setup of aseptically processes in medical science allowed the possibility of high-level surgery over the last century, with the hope of a safe healing. In return, major problems have appeared as nosocomial infections due to bacterial biofilm formations on medical devices $[1,2]$. Despite the multiplication of surgical procedures in order to get as close as sterile environment, bacterial contamination remains an important risk. Bacteria could indeed acquire antibiotic resistances and an emergence of multidrug resistant strains is observed [3,4]. Moreover, the most alarming is that bacteria with regular sensitivity to antibiotics are even able to develop a strategy to survive: the formation of a strong com- 
munity named biofilm $[1,2,5]$. Biofilm-associated infections represent $80 \%$ of nosocomial infections, and Staphylococcus aureus is the leading species in this domain [6-8].

Biofilm is defined as a multicellular lifestyle, an organized structure built by almost all bacterial species. Even if the term "biofilm" has been used for more than 60 years, the understanding of this structure started but recently. Fossilized biofilms of 3.5 billion years have been discovered and highlight the hypothesis that biofilm is a survival strategy always used by microorganisms since the dawn of time [5]. Scientists have recently understood that bacteria are not always living as free cells in nature; on the contrary, most of the time, bacteria build a real social life in a resistant community surrounded by a matrix composed of polysaccharides, extracellular DNA, proteins, lipids and other components [1, 2]. Biofilm is present on biotic or abiotic surface and bacteria embedded inside are 10-1000 times more resistant to conventional antibiotics than free-floating bacteria according to the strains, the molecule applied and the model of study [7-9]. Life cycle of biofilm is nowadays well-described. First, bacteria adhere on a surface and they enhance different mechanisms to irreversibly be attached. Then, the program of biofilm starts with a maturation of the multicellular structure. To complete this cycle, dispersion of swimming cells occurs under specific conditions [1, 2, 7-9]. However, the key of biofilm mechanism is the initiation that leads bacteria to form a biofilm and only under specific conditions. This trigger of biofilm mechanism is still an important question. Survival would be the answer, thus biofilm structure allows bacteria to resist to any types of environmental stress including UV, lack of nutrients and presence of antimicrobials [1, 2, 7-9].

All these characteristics lead to major problems in industries as well as in the medical domain. In industry, for example, the presence of multispecies biofilms has a high impact on the processes or on the production and results in high costs. S. aureus can be isolated from biofilm found in food industry particularly in dairy process [10], and they are sanitizers resistant [11]. As a consequence, microorganisms can infect the milk or other food products and cleaning the production system is very complicated or impossible. Thus, all the structures need to be replaced representing an important waste of money.

In the medical domain, numerous difficulties to treat biofilm-associated infections are described: resistance to antibiotics and to immune system, spread of infection, sepsis shock and surgical risks to remove infected implant or tissues $[1,6,8]$. S. aureus is one of the most frequent germs found in biofilm-associated infections partially resulting from the fact that they are commensal bacteria on the human skin and mucous [12]. Moreover, S. aureus multidrug resistant like methicillin resistant $S$. aureus strains (MRSA), is responsible for biofilm infections that are more difficult to treat that need more intensive care and replacement of medical devices as compared to Staphylococcus epidermidis biofilm infections, for example. S. aureus also embodies an important reservoir of dissemination to other human body sites [12]. Consequently, the development of new therapeutic strategies, through a better understanding of biofilms, is necessary and imperative [4] to fight against this structure resistant to the immune system and antimicrobial drugs.

Here after, to better understand the strength of S. aureus biofilms, different aspects relevant to biofilm, its mechanism and its physiology will highlight the aspects that are specific to 
Staphylococci and S. aureus more precisely. The consequence of S. aureus in clinical domain will be described and some "anti-biofilm" strategies will be suggested.

\section{Biofilm life cycle}

Different steps of biofilm life cycle have been well-described through the study of different bacterial species: reversible adhesion, irreversible attachment, maturation and dispersion [5, 13] (Figure 1). First, active bacteria can turn from "swimmers" to "stickers" on a support. A surface is supposed to always be in favor of adhesion because of the prediction that organic substances will concentrate on a surface and microorganisms will easily adhere and be protected from outsider challenges. Adhesion will dependent on the species of bacteria, surface composition, environmental factors, and essential gene products [14]. Microorganisms could adhere on inert or biotic surfaces. Most of the time, interaction between bacteria and abiotic surface involves nonspecific interactions as opposed to active interaction between microorganisms and live tissues [14]. The surface conditioning is quite important through various physiochemical parameters: hydrophobicity, chemical composition of the material, surface energy, eletrostatic charges, temperature, surface roughness and in the case of biotic adhesion: serum and tissue protein adsorption [14, 15]. Hydrophobicity increases bacterial adhesion in most cases $[15,16]$. In some environmental conditions, macromolecules adsorption could form a "film" neutralizing excessive charges and surface free-energy facilitating bacteria and surface proximity. It was shown that $\mathrm{pH}$ parameters influence $S$. aureus adherence on glass [17].

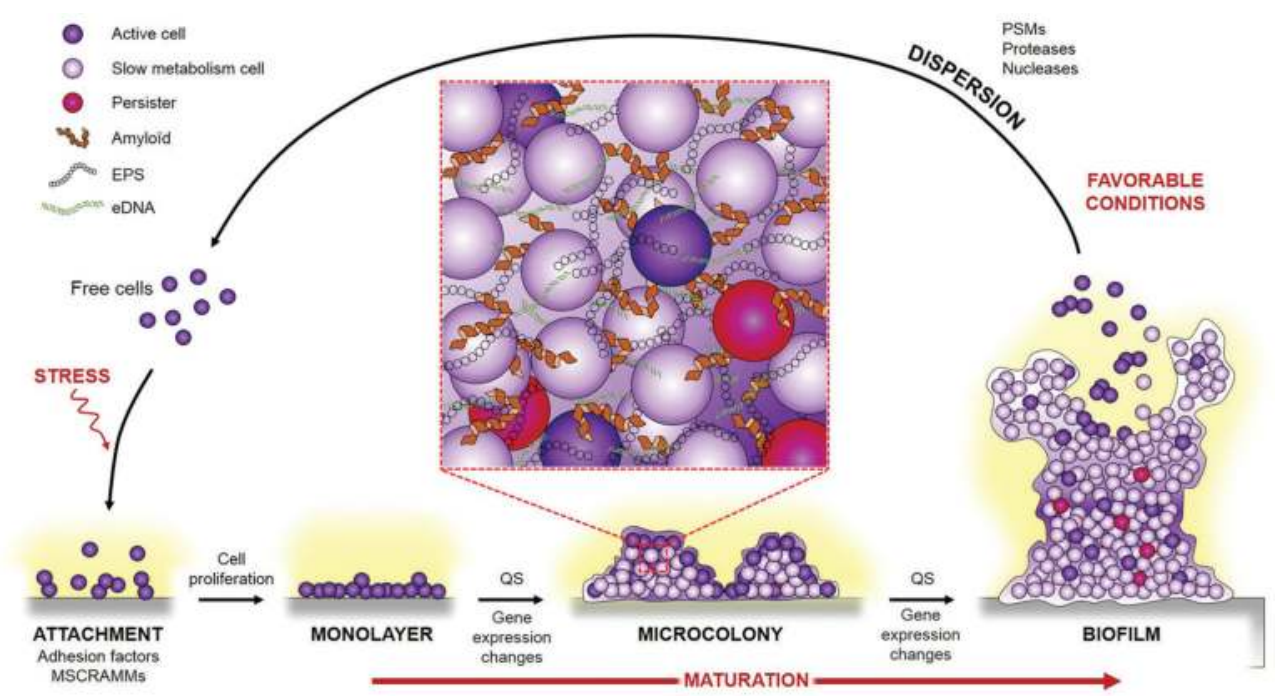

Figure 1. Biofilm life cycle. 
As far as S. epidermidis is concerned, Sousa et al. [15] have shown that surface conditions influence bacterial adhesion but the cell surface hydrophobicity itself was not linked to adhesion capacity, underlying the importance of other factors as cell wall associated proteins. The first bacteria approaching a surface adhere to it because of good conditioning but afterwards when the rate of cells increases, the following bacteria tend to adhere to previous bacteria instead of the surface [15]. In a case of a bad conditioning of surface and the necessity of adhesion, pili or other bacterial appendices could overcome potential repulsion.

\subsection{Attachment on a surface}

In any case, the life of a biofilm starts by an adhesion. The latter is reversible but can turn irreversible. Indeed, under specific conditions, events of irreversible attachment tend to increase and lead to the formation of a biofilm. In fact, irreversible attachment is the first step to the maturation of a future biofilm.

At the beginning, adhesion is the fortunate meeting between a good conditioned surface and a bacterium. In any environment, microorganisms can randomly get close to the surface or be attracted by chemotaxis involving their motility system [14]. Very recently, the ability for motility was observed for $S$. aureus even if they do not possess any appendages for movement [18]. This very particular movement is supposed to be a response to very specific conditions.

A surface could be attractive or repulsive for bacteria according to different parameters described above including hydrophobic and electrostatic interactions, hydrodynamic forces and temperature. Hydrophobicity is considered the most important. Bacteria could adhere on a biotic or abiotic surface thanks to the involvement of specific bacterial surface molecules such as the surface protein autolysin or the teichoic acids, altering the physicochemical properties of the bacterial surface rather than mediating the attachment via specific, receptor-mediated interactions [13].

In the human body, S. aureus is known to have specific targets in relation with its pathogenesis. Staphylococci attachment to a biotic surface such as human tissue is due to specific interactions with its virulent factors (Figure 1). These bacteria possess a large variety of surface-anchored proteins such as the microbial surface components recognizing adhesive matrix molecules (MSCRAMMS). MSCRAMMS are structured in three parts: a binding domain, a cell wall spanning domain and a third part responsible for the covalent or non-covalent attachment of the MSCRAMM proteins on bacterial surface. These adhesins are able to bind to one or several different human matrix proteins (fibronectin, fibrogen, etc.) $[13,19,20]$ and are required for biofilmassociated infections on indwelling medical devices covered by host matrix right after insertion [13]. Covalent bonds are catalyzed by sortases recognizing LPXTG motifs. S. aureus strains have a high variety of LPXTG-type MSCRAMMs compared to S. epidermidis [21]. Other surface proteins involved in adhesion are Sdr proteins (Serin-aspartate repeat family) or Aap (accumulation-associated proteins) [13]. Non-covalently bounds are insured by other proteins such as the autolysin Atl. Autolysins, involved in cell wall turnover, are one of the most abundant proteins on the staphylococcal cell surface and possess binding sites for human matrix proteins [22, 23].

Staphylococci are known for their high ability to stick to plastic surfaces. Teichoic acids, which are not involved in S. aureus attachment on biotic surface, are important compounds present in 
the cell wall and are important for adhesion on plastic surfaces thanks to their interaction with other surface polymers [13, 24]. However, in vitro assay over-estimated the interactions between teichoic acids and devices mainly because devices in fluids or in tissue are rapidly covered by host matrix proteins preventing the direct interaction of teichoic acids to plastic. Despite teichoic acids, two other adhesins have a role for adherence on plastic: the cell wall bound surface protein Bap involved in adherence to polystyrene surfaces [25] and SasC a S. aureus surface protein involved in attachment on polystyrene that does not mediate binding to fibrinogen, thrombospondin-1, von Willebrand factor or platelets [26]. Also, autolysins facilitate attachment to plastic in addition of their capacity to bind to human matrix and their enzymatic function [23].

\subsection{Communication between bacteria}

Pseudomonas aeruginosa biofilm is one of the most studied biofilm models. A powerful system of communication between cells was described in P. aeruginosa biofilm and named "quorum-sensing" [27]. First the quorum-sensing system was linked to a communication based on cell density. Then, quorum-sensing is virtually connected to biofilm formation and dispersal phenomena. The communication system in P. aeruginosa is based on molecules called acyl-homoserine lactones (AHLs) which penetrate bacteria and directly regulate target genes. Quorum-sensing systems have been described in Gram-negative and Gram-positive bacteria. Each quorum-sensing system is composed with different molecules and can activate or inhibit biofilm formation. The most studied system in S. aureus is the Agr quorum-sensing system but other systems of communication exist.

For S. aureus, only one specific quorum-sensing system was so far described, but most probably, there are other mechanisms for communication. At some point, some genes involved in $S$. aureus virulence were named accessory genes, and an accessory gene regulator (agr) was identified as a global regulator of virulence factors genes. Different experimental designs have shown that the Agr system induced by an extracellular ligand, the autoinducing peptides (AIP), is a sensor of population and so considered as a quorum-sensing system. This system can be activated by addition of AIP or by glucose depletion [28]. Briefly, this system is composed of two promoters P2 and P3. P3 transcript encodes RNAIII, the intracellular effector of target gene regulation, answering to agr system activation. P2 operon encodes for a two-component system and its autoinducing ligand AIP [29].

During biofilm formation, Agr quorum-sensing system is repressed to stop the expression of S. aureus colonization factors [29], and it gets activated during the dispersion of the bacteria [30]. Artificial activation of Agr has also been shown to induce biofilm dispersion [28]. Moreover, Agr quorum-sensing system is necessary for the communication inside mature biofilm to establish the 3D structure through the control of cell dispersion. This probably requires phenol-soluble modulins (PSMs) which are described in the next section and proteases activated by Agr and involved in the degradation of exopolysaccharides (EPS) matrix [31]. However, Agr does not control important biofilm adhesive molecules such as the polysaccharide intercellular adhesions, currently named PIA [32]. In conclusion, Agr system regulation is based on cell density. During the early stage of colonization, cell density is low and as consequences Agr quorum-sensing activity gets weak and the cell wall protein or surface 
adhesins are not downregulated but highly expressed. In the later stage, Agr activity increases with cell density and thereafter Agr upregulates secreted virulence factors such as lipases, proteases and hemolysin [33]. Not surprisingly, Agr involvement in biofilm formation seems to be under specific environmental conditions as shown by the contradiction of experimental results relevant to the model used in the study [30]. One problem underlined each time is the difficulty to detect agr expression due to the very slow bacteria metabolism in the biofilm. During hospitalization, $S$. aureus strains isolated from patients are more frequently Agr-defective strains showing their better ability to turn into a nosocomial infection agent [34]. Some agr-defective mutants have been isolated from catheter infections, where they had the capacity to form a compact biofilm with the loss of their capacity to detach and disseminate.

Other regulators have been identified such as Rbf which is involved in S. aureus biofilm formation at the maturation stage rather than at the initial attachment [35]. This regulator did not affect ica gene locus coding for adhesins; however, a clinical isolate with $r b f$ mutation showed a lower capacity to form biofilm. LuxS, another regulator first described in Vibrio cholerae, is under the control of the auto-inducer AI-2 and seems to play a role in biofilm formation through the icaR expression. However, LuxS is also involved in the S-adenosyl methionine cycle, and its role in biofilm is consequently debated as it could be the result of this metabolic role [36].

In conclusion, production of surfactant molecules dependent of quorum-sensing system appears to be a general mechanism for the biofilm structuring as well as for the detachment of many bacteria. In the specific $S$. aureus quorum-sensing, biofilm is based on the detection of signaling molecules by specific sensors which lead to a chain reaction with different molecular actors and not on a direct communication where the signal molecules enter in the cells and directly regulate different genes. In S. aureus, the sensors are numerous and allow a fast answer of the bacteria.

\subsection{Maturation}

The maturation of biofilm is based on the development of the multicellular structure (Figure 1). Biofilm growth is controlled by the increase of bacterial mediators, the slowdown of metabolism and cell cooperation. Maturation starts when bacterial cells induce the biofilm program and create an intercellular aggregation through the production of a "slime" commonly named matrix. The latter sticks bacteria one to each other as well as on surface. The matrix is composed of exopolysaccharides (EPS), proteins and extracellular DNA (eDNA) and is responsible for biofilm maturation that is the result of an organized community construction. This specific 3-dimensional structure appears as a typical mushroom-like shape containing water or fluid channels formed thanks to a disruptive process [37]. Paradoxically, maturation in the construction of the community needs also disruption events. Fluid-filled channels are vital in delivering nutrient into biofilm deeper layers [38]. This kind of structure is species-specific.

Exopolysaccharides are the first molecules discovered in biofilm matrix. In staphylococci, the most described adhesive biofilm molecule is the polysaccharide intercellular adhesion (PIA) or poly-N-acetylglucosamine (PNAG) and represents the major part of the staphylococci biofilm-forming extracellular matrix [39]. PIA has an important role in the biofilm structure and 
the biofilm-associated infections [40, 41]. Introducing a positive charge in the environment of the bacterial cell surface which is negatively charged, PIA works like a glue sticking the cells together by electrostatic interaction [42]. PIA is encoded by ica gene locus and regulated by numerous environmental factors [43]. For example, SarA and SigB upregulate PIA expression and on the contrary LuxS downregulates it [44-46]. PIA is the only factor identified so far as important for staphylococci biofilm formation in vivo [13, 43]; however, PIA is not present in all strains isolated from biofilm-associated infections [47]. Therefore, some other compounds like proteins must also play a role.

Numerous specific proteins could be substitute for PIA in biofilm formation as proteins are now recognized as essential for biofilm structure, such as the following proteins: Aap (accumulation associated protein), extracellular matrix binding protein (Embp), protein A, fibrinogen-binding proteins (FnbpA and FnbpB) or S. aureus surface protein $G$ (SasG) [48]. This latter mediates intercellular aggregation thanks to hydrophilic interaction with the proteins present on other bacteria [49]. As for S. aureus surface protein SasC, which possesses a LPXTG-motif to anchor to cell wall, it is involved in intercellular aggregation and biofilm maturation [26]. Depending on the Staphylococcus, the extracellular Aap protein [50] is involved in PIA-independent biofilm formation in S. epidermidis [51] or in the maturation of the biofilm by interactions with PIA like in S. aureus [50].

All these results underline the importance of the surfactants in biofilm maturation. Phenolsoluble modulins (PSM) are surfactant peptides found in both S. aureus and S. epidermidis. Their sequence is species dependant, but they all have an amphipathic $\alpha$-helix [13]. PSMs are strictly controlled by Agr, with a direct binding of Agr regulator on the $\mathrm{psm}$ operon promoter, suggesting that Agr-dependent biofilm maturation processes are due to PSMs expression [13]. Moreover, an agr mutant strain of $S$. aureus has the same behavior that a completely deleted PSM genes mutant in in vivo model [13]. As shown in S. epidermidis, the PSM involvement in biofilm maturation is independent of the PIA protein. In S. epidermidis, the lack of PSMs leads to biofilms that are more "compact", suggesting that PSM are also involved In biofilm development. Furthermore, as seen in all the Staphylococcus, the presence of the PSM peptides is needed for biofilm volume, thickness, roughness and channel formation [52]. Surfactant peptides are therefore the key of the 3-dimensional biofilm structure. PSMs also induce biofilm detachment [52] and are biofilm maturation in vivo determinant factors [13].

Amyloid proteins have also been revealed as important for biofilm structure, bringing stability to the matrix [53]. These protein fibers could bind the extracellular DNA. PSMs play also a role as inert fibrils in biofilm, acting as a solid bond, waiting for better conditions to induce their dissociation and promote biofilm dispersion [53, 54]. Bap another cell wall bound surface protein [25, 55-57], involved in adhesion, is also required for biofilm maturation and infection of bovine mammary glands [20,45]. This protein is a real sensor, responding to environmental conditions (like calcium concentration), and Bap is also a scaffold protein forming amyloid-like aggregates at low calcium concentration and under acidic $\mathrm{pH}$ [53].

Under an organized construction, biofilm maturation is based on development and disruption events. Thus, PIA-degrading enzymes (PIAse) are supposed to contribute to biofilm maturating but they have never been found in staphylococci [13]. Anyway other proteases could 
have an important role in staphylococci biofilm maturation as proven by strains showing PIA-independent biofilm formation [58]. Those proteases are regulated mostly by SarA and more rarely by Agr, but so far no experiments have demonstrated direct evidence for their role on biofilm development or protease-mediated biofilm detachment.

The third important element of matrix composition is extracellular DNA (eDNA). DNA, a polyanionic molecule present in biofilm matrix, is described as a ligand able to link to other molecules present in the matrix such as teichoic acids or PIA. Therefore, DNA has a role in biofilm structure. This presence is based on the involvement of cell death: DNA released from lysed bacteria also called eDNA has a critical involvement during initial attachment and maturation. An increase of cell lysis influences biofilm formation through the Cid proteins [59-61]. Indeed, regulators like CidR which controls autolysis are involved in biofilm development and the formation of the tower mushrooms shapes [62]. Extracellular DNA appears through the bacterial programmed cell death and through the expression of $c i d A$ gene encoding for a holin responsible for lysis. This system is regulated by the production of an antiholin encoded by $\operatorname{lrg} A B$ genes which is an inhibitor of cidA-mediated lysis [59, 62]. However, in vivo, the importance of eDNA is difficult to assess as well as to understand how a staphylococcal biofilm could survive in the presence of human DNAseI which succeed to disperse a mature biofilm in vitro [13].

In conclusion, scientists have realized how important it is to have precise knowledge of the mechanisms involved in the biofilm extend matrix or in the detachment steps to be able to develop anti-biofilm strategies. However, biofilms are also formed by four set of cells: some with an aerobic or fermentative growth, some dormant or dead [63]. This cell heterogeneity within the biofilms has to be kept in mind in the search of anti-biofilm therapy.

\subsection{Dispersion}

Disruptive processes are vital for biofilm structure and disruption allows the detachment of single cells or large bacteria cluster from biofilm in case of good environmental conditions or in case of expansion of the biofilm (Figure 1). This dispersion has important consequences in biofilm-associated infections as it leads to systemic dissemination. It is well known now that detached cells from biofilm could lead to endocarditis or sepsis [13].

Disruption is based on mechanical forces as well as the interruption of the production of the biofilm material and production of enzymes and surfactants that are considered as detachment factors able to destroy the matrix. Agr quorum-sensing system involved in biofilm formation and extracellular protease activity are required to control biofilm dispersal molecules [28, 32, 52]. Expression of agr mostly carried out by the bacteria in the outer layers of the biofilm leads to detachment and regrowth [30], but agr is also expressed in deeper layers where it is required for channel formations [52]. In fact this dispersal effect linked to Agr system could be due to the involvement of PSMs whose expression is controlled by the Agr quorum-sensing.

Nucleases, the enzymes degrading extracellular DNA are also necessary. The human DNaseI degrades staphylococcal biofilms [64]. Staphylococcal thermonuclease nuc 2 is involved in the biofilm development probably to promote dispersion [65]. A second nuclease nuc1 showed 
the similar dispersal effect as nuc2 on biofilm in vitro [66]. Nevertheless, those effects are not detected so far in in vivo models [66].

Other factors, involved in dispersion, have been described such as bacteriophages which have been revealed as important for biofilm development, especially in dispersal stage [31]. Even proteases like Aur metalloprotease and Slp serine protease have been shown to be responsible of dispersal movement [67].

In conclusion, biofilm life cycle starts under the impulse of a stress response (e.g., starvation) and bacteria attach on a surface where cell proliferation is more favorable. A monolayer is formed, and some specific genes are expressed inducing the production of microcolonies. Quorum-sensing system acts as a supervisor, and biofilm is formed in a well-organized structure.

\section{Physiology of biofilm}

Biofilms seem to be the best strategy for bacteria to survive to any kind of environmental stress. The detection of stress and thus the response needs to be fast enough to survive under those conditions. Therefore, the rapid process of activation of the biofilm program is crucial for the bacteria.

\subsection{Program on/off}

As described for stress response, the setup of inducible processes is based on the differential expression of an important number of genes [68,69]. Biofilm bacteria cells are physiologically different from free cells [12]. Indeed, the different steps as adhesion and immobilization need the expression of various genes. More important, the communication between bacteria (quorum-sensing system) controls many metabolic systems and leads to regulation of many genes. The production of the quorum-sensing molecules as an endogenous signal leads to changes according to the detected concentration. Environmental clues trigger genetic and physiological changes also called biofilm transition. As previously described, the matrix is the plinth of biofilm development and is responsible for many processes in the biofilm program. Moreover, biofilm cells show a general downregulation of their metabolism underlining the slow growing cell or the lack of oxygen due to the biofilm structure, like during fermentation. An upregulation of the urease and the arginine deiminase pathway to limit the side effects of the acidic $\mathrm{pH}$ during anaerobic growth was also observed in biofilm structure [12]. All those adaptations participate to a general biofilm setup process. The differential gene expressions also lead to antibiotic resistance mechanism. In S. epidermidis, some of these antibiotic resistance mechanisms are upregulated during biofilm stage [70]. In S. aureus, Agr expression and involvement in biofilm formation depend of the environmental conditions [30]. The agr expression shut down has no effect, enhances or inhibits biofilm formation according to the environmental parameters [30].

Biofilm program is a temporary response to stress conditions and this process is able to turn off quite quickly when conditions are more favorable for the bacteria. 


\subsection{Interactions with the environment and survival strategy}

Bacteria have the extraordinary ability to survive in any harsh conditions, and as recently discovered, this is due to their capacity to form biofilm. Many environments can be a source of stress for bacteria. S. aureus biofilm have been found in industry and in clinical domain, particularly in biofilm-associated infections. Environmental stresses are supposed to induce biofilm formation. As evidence, sigma $\mathrm{B}$, a protein required for transcription and activated under stress responses due to heat shock, $\mathrm{MnCl}_{2}, \mathrm{NaCl}_{2}$ and alkaline shock, is involved in biofilm formation [71, 72].

In S. aureus, nutrients like glucose or $\mathrm{NaCl}$ can influence biofilm. For example, Rbf regulator is involved in biofilm formation under high concentrations of glucose and $\mathrm{NaCl}$ conditions, but not in the presence of ethanol [35]. Nutrient-starvation has been underlined as an important environmental stress which could induce biofilm maturation [61, 73]. In vitro, however, the addition of glucose is required for biofilm formation and activation of the agr quorum-sensing system [28], even if oldest results showed the contrary [74]. In fact, conditions to form biofilm seem to be very specific, such as a balance between an over-concentration of glucose and a lack of carbon source. The $\mathrm{pH}$ maintenance also influences Agr system and, in consequence, probably acts on biofilm formation [74, 75].

Nitrite stress also induces PIA expression, responsible for the major part of the matrix composition [76]. In fact, induction or repression of biofilm formation is due to a balance of concentration of specific nutrients or stress. For example, NO is necessary for biofilm formation until its concentration starts to be too high. Thereafter, NO is involved in the dispersion of the biofilm [77]. It has also been observed that low oxygen, even anaerobic state, like in the heart of the biofilm, increases PIA expression [78].

In human body, the lack of nutrients (e.g., iron, carbon source, etc.) or oxygen, the presence of the immune system or even the antimicrobial molecules are felt by the bacteria as stresses and could induce biofilm program. In S. aureus, PIA expression and biofilm maturation are strongly inducible by conditions found in vivo as described in a device-related infection model [79]. In S. epidermidis, subinhibitory concentrations of tetracycline and quinupristin - dalfopristin induce ica gene cluster expression and the increase of $\mathrm{Mg}^{2+}$ concentrations increase biofilm production. On the contrary, the addition of EDTA (Ethylenediaminetetraacetic acid) decreases the number of cells on a plastic surface [14]. Zinc concentration might also influence biofilm adhesion through the activity of SasG a surface protein with zinc-dependent mechanical properties [49]. Subinhibitory concentrations of furanone, molecules isolated from red algae, inhibit quorum sensing but also favor biofilm formation [80, 81]. This result reflects the possible inter-species interaction domain and the importance of the specific microenvironment.

In nature, many bacteria live under nutrient-limited conditions, lack of oxygen and under many other dangers like humidity, osmotic pressure and mechanical forces. Biofilm through the presence of the matrix protect all the embedded bacteria from all those environmental variations and pressures.

\subsection{Interactions with the host immune cells}

During bacterial infection, host immune cells are the defenders of the organism. Through mechanisms such as phagocytosis or release of bactericidal components, these cells are able 
to fight and neutralize planktonic $S$. aureus. Concerning S. aureus biofilm, the general thought is that biofilm structure protects the bacteria against the immune cells, avoiding interaction between both actors. Nevertheless, recent studies reported that polymorphonuclear neutrophils (PMN), macrophages, myeloid-derived suppressor cells (MDSCs) and T lymphocytes can interact with $S$. aureus biofilm in a double-edged interplay (Figure 2).

PMNs are the first line of defense in bacterial infections. These cells can phagocyte planktonic bacteria and release bactericidal components such as reactive oxygen species or enzymes [82]. Contrary to the dogma, in vitro experiments revealed that PMN can also attack S. aureus in biofilm form. PMNs can migrate towards and into the $S$. aureus biofilm and clear it by phagocytosis. The extent of biofilm clearance is apparently depended on its maturation state. Indeed, mature biofilms were reported as more resistant to phagocytosis as young ones [83]. Following phagocytosis, PMNs underwent apoptosis, a programmed cell-death in order to prevent spilling of the bactericidal and cytotoxic entities [84]. In addition to phagocytosis, PMNs can release lactoferrin and elastase through degranulation phenomenon, as well as DNA [85]. Oxygen radical production by the PMNs also participates to biofilm clearance and is depended on the coating of biofilms with IgG, a mechanism termed "opsonization" [86]. In a global manner, PMNs can be considered as an asset to fight against $S$. aureus biofilms.

In parallel to PMNs response, a macrophage response is also triggered during S. aureus infections, which is altered in case of $S$. aureus biofilm infection. Indeed, planktonic S. aureus normally induces a proinflammatory microbicidal phenotype in macrophages defined as M1. It implies the phagocytosis of bacteria and the production of bactericidal components [87]. In the context of $S$. aureus biofilm infection, in vitro and in vivo studies reported that invasion of macrophages into biofilms is limited. S. aureus biofilms is able to secrete specific toxins

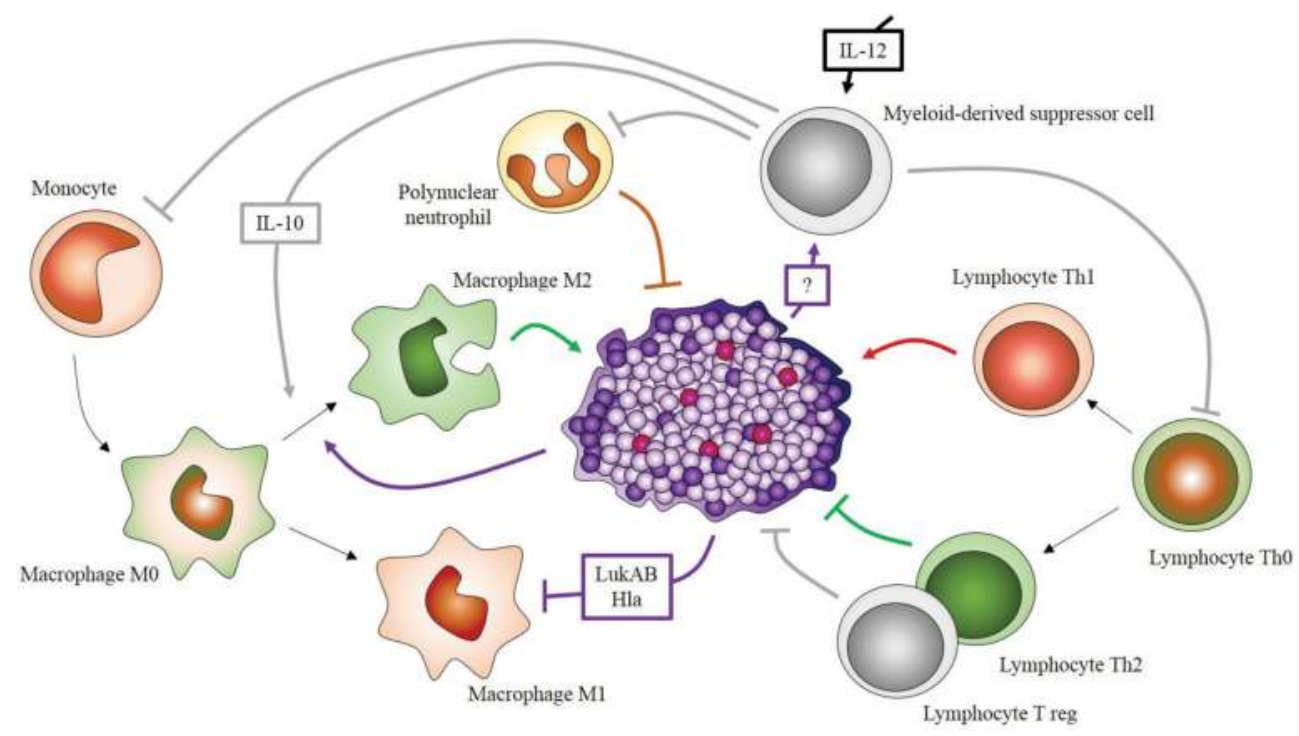

Figure 2. Interplay between S. aureus biofilm and host immune cells. 
called alpha-toxin (Hla) and leukocidin $\mathrm{AB}$ (LukAB) that inhibit macrophage phagocytosis and induce cytotoxicity, promoting macrophage dysfunction and thus facilitating $S$. aureus biofilm development [88]. Moreover, S. aureus biofilm can also induce the polarization of macrophages from a proinflammatory microbicidal M1 phenotype to an alternatively activated M2 phenotype, displaying anti-inflammatory properties and limited phagocytosis [33, 89]. A recent study showed that the treatment of established biofilm infections with M1-activated significantly reduced biofilm burdens, supporting that M1 phenotype is unpropitious to $S$. aureus biofilm development whereas M2 polarization favors it [90].

The most recent studies concerning interactions between S. aureus biofilms and immune cells focus on the MDSCs, a heterogeneous population of immature monocytes and granulocytes with immunosuppressive properties. In case of $S$. aureus biofilm infection, MDSCs prevent monocyte/macrophage pro-inflammatory activity, inhibit $\mathrm{T}$ lymphocytes proliferation and facilitates biofilm persistence [91]. This phenomenon is in part orchestrated by the interleukins IL-12 and IL-10 $[92,93]$. IL-12 is a cytokine with both pro- and anti-inflammatory properties that promotes the recruitment of MDSCs whereas IL-10 is an anti-inflammatory cytokine, mainly produced by MDSCs in context of biofilm infection. A recent study reported that IL-10 promotes biofilm growth and anti-inflammatory gene expression in monocytes, which can be assimilated to a polarization to M2 phenotype [93]. MDSCs would in the end be the effectors for the development of the anti-inflammatory environment that favors S. aureus biofilm persistence.

Concerning interactions between S. aureus biofilm and T lymphocytes, Leid et al. reported that mononuclear leukocytes, especially lymphocytes and in a lesser extend monocytes, can attach to the biofilm but they are not able to phagocyte maturing and fully matured S. aureus biofilm [94]. In case of S. aureus biofilm infection, early Th1 and Th17 inflammatory responses are increased and Th2 as well as Treg responses seem downregulated [95]. Th2/Treg responses appear as a protection mechanism for the organism as opposed to Th1/Th17 responses, which may favor the development of chronic S. aureus biofilm infection [96]. This response, in opposition to what is observed in the macrophage response, reveals the complexity of the interactions between $S$. aureus biofilms and the cells of the immune system.

\section{S. aureus biofilm-associated infections and antibiotic treatments}

\subsection{S. aureus biofilms are responsible for different types of infection}

Different bacteria are involved in infections associated with biofilm development in immunocompromised patients or medical devices. Sadly, the most famous example is P. aeruginosa species which develop highly resistant biofilm in pulmonary tract of cystic fibrosis patients.

Biofilm formation is linked to various staphylococcal diseases such as endocarditis, osteomyelitis, skin and soft tissues infections, urinary tract infection, nasal colonization and cystic fibrosis complications as well as implant-associated infections [97-99]. In most of the case, the production of biofilm favors the chronicity of $S$. aureus infections. The colonization of implanted materials by staphylococcal biofilm is one of the highest important issues. 
Staphylococcal biofilm can develop on various structures such as catheters, prosthetic joints, prosthetic heart valves, contact lenses, cerebrospinal fluid shunts and cardiac pacemakers [100]. Furthermore, after their implantation in the body, medical devices become coated with host proteins, facilitating the attachment of $S$. aureus and the biofilm formation [101].

\subsection{S. aureus biofilm-associated infections are more resistant}

Biofilms have shown unbreakable structures resistant to antibiotics and many other molecules or environmental stresses. Many hypotheses have been tested to explain this incredible natural invincibility. First, the intrinsic structure of biofilm supposes that antimicrobials could not penetrate inside the biofilm. This hypothesis has been revealed unlikely for most of the antibiotics as the biofilm structure is composed with many water channels. A second hypothesis is based on the fact that the biofilm matrix can accumulate antibiotic-degrading enzymes, and in consequence, antibiotics are quickly destroyed [9]. Then, scientists underline the fact that microorganisms have a very slow metabolism in the biofilm preventing most of the kinetic responses involved in the antibiotic mechanism. The use of antibiotics targeting more specifically those slow growth bacteria was not more successful, even combined with antimicrobial drugs that could target active bacteria present in the biofilm population, known to be heterogenic [63]. Persister cells can also be present in this heterogeneous population and can withstand high concentration of antimicrobial drugs.

Nowadays, it seems that the natural resistance of biofilms comes from the induction of specific biofilm mechanisms [9]. Stress responses, as biofilm formation, lead to the changes of many gene expressions which increase the antimicrobial resistance. Nutrient starvations are now known to favor antibiotic tolerance [61].

Biofilm is the perfect example of an adaptive resistance, not due to a genetic mutation that could be transferred to daughter cells, even if the bacteria proximity in the biofilms increase horizontal transfer gene or mutation that could lead to intrinsic resistance [9].

\subsection{Current treatment of $S$. aureus biofilm}

Treatment of $S$. aureus biofilm is a therapeutic challenge. Even if everybody has in mind that the embedment of $S$. aureus in slime gives him an increased tolerance to antibiotics, two situations have to be defined concerning the treatment of $S$. aureus biofilm-associated infections.

Firstly, antibiotics can have an inhibitive effect on the formation of biofilm. It is related to the capacity to inhibit the attachment and the initial growth of the biofilm. A recent study specifically evaluated the inhibition of $S$. aureus biofilm formation through the use of a new system the antibiofilmogram ${ }^{\circledast}$ [102]. Based on Biofilm Ring Test ${ }^{\circledR}$ method [103], this system permits to define, for a chosen antibiotic, the minimal inhibiting concentrations (MIC) needed to inhibit biofilm formation (called bMIC). In this study, Tasse et al. reported that the bMIC is equivalent or close to the MIC for planktonic bacteria. Similar values between MIC and bMIC were notably observed for clindamycin, fusidic acid, linezolid and rifampin [102].

The second situation concerns the efficiency of antibiotics on formed/mature biofilm. The sessile community is already organized and persisters can be present. In this case, antibiotic 
efficiency is defined through the measure of the minimal biofilm eliminating concentration (MBEC) via the use of the Calgary Biofilm Device [104]. MBEC for S. aureus biofilms can be 10-1000 times higher than the MIC defined for planktonic bacteria, depending on the investigated strains and antibiotics [105-108].

The difference between bMIC and MBEC is probably due to a lack of penetration/diffusion of antibiotics inside the biofilm, even if this statement still stays controverted. Indeed, a decreased penetration of antibiotics has been observed in in vitro models of $S$. aureus biofilm $[109,110]$. The penetration inside biofilm varies depending on the type of antibiotics and the structure of the biofilm. On the contrary, other studies, such as the recent one by Boudjemaa et al. reported that the biofilm matrix was not a shield to the antibiotic diffusion. They observed that the concentration inside the biofilm is similar to the one that could be found outside the biofilm. In this case, the resistance to the treatment would be related to a decreased effect of the drug to $S$. aureus $[98,111]$. An interesting compromise can be that several factors influence the efficiency of antibiotic treatment against S. aureus biofilm. Lack of penetration is one of them but cannot be the only answer by its own.

With regards to this, the combination of antibiotics appears as an interesting solution for an effective treatment. Susceptibility test revealed that rifampin, but also vancomycin and fusidic acid were the most interesting constituent of antibiotic combinations active against the staphylococcal biofilms [112]. In an innovative in vitro model, Parra-ruiz et al. demonstrated that the combination of daptomycin or moxifloxacin with clarithromycin is of greater effect than the individual effects of the three agents against a biofilm formed by a methicillin-sensible S. aureus (MSSA) strain. Similar observations were made for the combination of linezolid and daptomycin as well as for daptomycin and rifampicin against a MRSA strain $[113,114]$. However, recent studies suggested that combination of antibiotics could also have an antagonistic effect on the elimination of $S$. aureus biofilm. It was reported that linezolid can antagonize vancomycin and daptomycin activities [115]. In an infective endocarditis model of biofilm-forming MRSA, Laplante and Woodmansee observed that rifampin and gentamicin antagonized or delayed the bactericidal activity of daptomycin and that daptomycin monotherapy had better in vitro activity than vancomycin-containing combinations [116]. Moreover, according to Croes et al., the use of rifampin-containing combinations against $S$. aureus biofilm remains unpredictable, ranging from a tendency toward antagonism to some synergism effects [117]. At the opposite, a recent study, analyzing the antibiotic susceptibility of 58 clinical isolates, emphasized that there are no evidence for advice against the daptomycin/rifampin combination therapy for MSSA/MRSA infection.

The efficiency of antibiotic monotherapies or bi-therapies was most of the time evaluated through the use of in vitro models. In vivo models of infection are of high importance to comfort and strengthen the results between the bench and the patient bed. In a MRSA joint prosthesis rabbit infection model, the combination of rifampin with daptomycin was observed to be more effective than a treatment of either of these agents [118]. Similar results were reported about the combination of linezolid with rifampin or vancomycin with rifampin in a rabbit model of MRSA foreign body osteomyelitis [119]. Recently, study tested several antibiotics alone and in combination in a murine model of implant-associated osteomyelitis. The authors 
reported that the most effective antibiotic combinations contained rifampicin and that the combinations containing two nonrifampicin antibiotics were not more active than single drugs [120].

Globally, trying to prevent the biofilm formation appears as the most interesting way to fight this kind of infection. In case of full-formed biofilm infections, using a combination of highdosed antibiotics containing rifampicin and/or daptomycin seems to be the best option.

In addition to the difficulties to treat biofilm-associated infection, there is also the important delay necessary to spot them. The emergency of finding a technical approach to detect biofilm in the analysis laboratories is huge. Some biomarkers have been searched, especially thanks to qPCR (quantitative polymerase chain reaction) techniques. For example, ica genes encoding for PIA can be identified by PCR [47]. However, ica operon is not present in all S. aureus strains [51], and therefore, it cannot be used as a general biomarker. There still is a lack of tool in the diagnosis of biofilm associated infections. It would be necessary to find either a universal biomarker that defines all biofilm species or at least, a biomarker species-specific detectable in the particular case of the biofilm presence.

\section{Future strategies to fight against biofilm formation}

Nowadays biofilm existence cannot be ignored anymore. Scientist community has to find new ways of fighting this bacterial social network as to avoid biofilm formation, or to weaken its intrinsic resistance, to disrupt biofilm or to kill bacteria embedded in this structure as detailed by Bjarnsholt et al. [121] and summarized in Figure 3.

\subsection{Prevention by antiadhesive or anticommunication molecules}

Prevention will always be the best strategy to fight against biofilm formation. Moreover, inhibiting the biofilm formation, bacteria stay under "planktonic" form and are much more susceptible to antimicrobial or immune system molecules, and therefore easier to eliminate. Prevention has to be used as a prophylactic strategy, especially for devices implant during surgery [121]. The idea is to avoid bacterial adhesion on material. As a consequence, some anti-adhesive surfaces are developed to be used in implant manufacturing [122]. For example, titan implants

$1 /$ PREVENTION

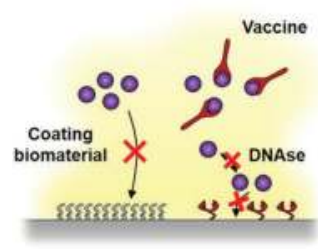

2/WEAKENING

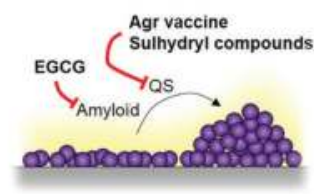

3/DISRUPT

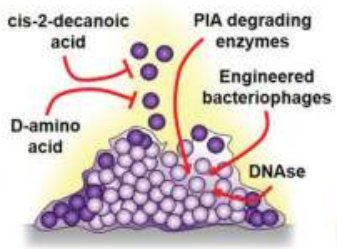

4/ KILLING

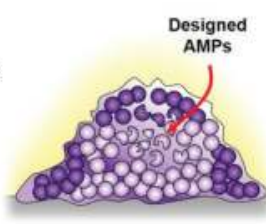

Figure 3. Strategies "anti-S. aureus biofilm." 
coated with gentamicin showed a local action and a short period release fighting S. aureus early infection and decreasing toxic side effect [123]. This strategy could be applied when the infection is not endogenous as the antibiotic release will end at some point and that the implant turns then again into a perfect bacterial support [121]. To prevent bacterial adhesion, it could be interesting to target molecules responsible of initial attachment as adhesins by using neutralizing antibodies [121]. A vaccine was developed based on 4 antigens involved in biofilm formation of $S$. aureus. Its efficiency was proved in chronic osteomyelitis rabbit model but only in combination with vancomycin to kill the free bacteria [124]. Inhibition of biofilm development could be also based on the use of enzymes degrading biofilm matrix components [121] such as DNase which avoid the irreversible attachment step but this strategy does not work in in vivo models. Inhibition of biofilm formation could be based on the perturbation of signal like the presence of endogenous nitrite or the addition of exogenous nitrite [76] or D-amino acids which disturb the initial attachment or the maturation. Moreover, surfaces impregnated with those molecules prevent device-related infection [125, 126]. Antiadhesive strategies are often designed for surfaces supporting an antiadhesive molecule which target and antagonized adhesin or other specific attachment molecules [122] avoiding any bacteria adhesion.

To conclude, the conceptualization of molecules interfering with signals responsible for biofilm program induction could be imagined and this could lead to the presence of only free-floating bacteria that are more susceptible to antibiotics.

\subsection{Weakening}

In case the biofilm prevention fails, other strategies have to be developed. Weakening strategies are based on the idea of avoiding the biofilm properties set up, being efficient only on biofilm in formation not on mature biofilm [121]. Targets of this strategy are virulence factors, communication molecules or specific metabolic pathway involved in biofilm maturation. In S. aureus, Agr quorum-sensing system and Agr-regulated PSMs are key controllers of biofilm structure. In consequence, they are the perfect targets for vaccines or drugs [28, 127]. RNAIIIinhibiting peptide negatively regulates quorum-sensing response, and in consequence, it can reduce $S$. aureus biofilms in vivo [128].

Molecules interrupting the production or assembly of amyloid fibers could consequently destabilize biofilm structure. The compound (-)-epi-gallocatechine gallate (EGCG) used to fight against amyloid peptides involved in Alzheimer's and Parkinson's diseases is also active to inhibit S. aureus biofilm [53]. Another example is the functional micro-domains which have been discovered in bacterial membranes and their inhibition through the application of zaragozic acid avoids biofilm formation [129].

It will be interesting to develop other vaccines or drugs which target virulence factors that enhance biofilm formation.

\subsection{Biofilm disruption}

As for "weakening" strategies, targeting Agr quorum-sensing system in S. aureus will be interesting for triggering disruption [28, 127]. Other molecules have been screened for their ability to disperse biofilm. A fatty acid messenger named cis-2-decenoic acid produced during 
$P$. aeruginosa growth has shown a capacity to disperse S. aureus biofilm [130]. D-amino acids trigger biofilm disassembly in affecting amyloid fibers and could be a potential strategy to disperse a preformed biofilm [125].

Another target to disrupt biofilm is the matrix, using for example, PIA-degrading enzymes. Two matrix polymers in staphylococcal biofilms poly-N-acetylglucosamine and eDNA could be targeted for their destruction by dispersin B and DNaseI, respectively. Dispersin succeeded in detaching pre-formed S. epidermidis biofilm but not S. aureus ones, and on the contrary, DNaseI induced a disruption of S. aureus structures and not S. epidermidis ones [62]. However, nucleases do not impact biofilm-associated infections [66]. Moreover, bacteriophages are known to be involved in biofilm dispersion stage [31]. Therefore, bacteriophages were engineered to produce dispersin B, and biofilm mass reduction was noticed [131, 132].

\subsection{Killing}

To eradicate a pre-form biofilm is the last chance and this strategy remains the most difficult to fathom. Many molecules have been tested but they have to respect many criteria like the non-cytotoxicity and the non-pro-inflammatory effects. Promising molecules are the "anti-biofilm" peptides inspired by animal antimicrobial peptides (AMPs) which have anti-inflammatory effects and are efficient to destroy Gram-positive or Gram-negative bacteria at very low concentrations [73, 133]. They have also shown their ability to act in synergy with conventional antibiotics, avoiding the use of too high concentrations of each molecule [133].

\section{Conclusion}

After the revolutionary discovery of antibiotics, the medical community thought that the battle against microorganisms was won. However, the fight had just begun as bacteria can develop resistant structure named biofilm among other strategies. S. aureus is one of the most common bacteria found on human epidermis thus when physical barrier such as skin is broken, $S$. aureus could penetrate and adhere to tissue or medical devices. Many S. aureus strains are drug-resistant (MRSA), and moreover, S. aureus represents the most frequent germ responsible of chronic biofilm-associated infection. The treatment against this kind of chronic infection is useless in most cases, especially against MRSA. S. aureus is also present in food infection and responsible of intoxication. For all these reasons, the understanding of $S$. aureus biofilm is necessary in order to develop new strategies to inhibit biofilm formation and/or to eradicate S. aureus biofilm. Nowadays, more and more molecular mechanisms are decrypted: bacterial communication, biofilm formation and dispersion. Consequently, new molecules are targeted but so far most of this targeting has revealed inefficient in in vivo models. Unfortunately, discoveries on biofilm in general and on S. aureus biofilm in particular, represent a drop in the ocean. Bacteria are simple organisms with complex mechanisms. We, scientists and physicians, have to integrate the fact that planktonic bacteria only reflect the optimal conditions of a laboratory environment. 'Biofilm is the real enemy, and it changes the all entire picture. New biofilm models have to be developed, especially in vivo models. 


\section{Acknowledgements}

We thank Kevin Delaitre for careful proofreading.

\section{Author details}

Fany Reffuveille ${ }^{1,2 *}$, Jérôme Josse ${ }^{1,2}$, Quentin Vallé1, 2, Céline Mongaret ${ }^{1,2}$ and Sophie C. Gangloff ${ }^{1,2}$

*Address all correspondence to: fany.reffuveille@univ-reims.fr

1 EA 4691, Biomaterial and Inflammation in Bone Site, Health Pole, University of Reims Champagne-Ardenne, Reims, France

2 UFR of Pharmacy, Microbiology, University of Reims Champagne-Ardenne, Reims, France

\section{References}

[1] Høiby N, Ciofu O, Johansen HK, Song Z, Moser C, Jensen PØ, et al. The clinical impact of bacterial biofilms. Int J Oral Sci. 2011 Apr;3(2):55-65.

[2] Costerton JW, Stewart PS, Greenberg EP. Bacterial biofilms: a common cause of persistent infections. Science. 1999 May 21;284(5418):1318-22.

[3] Boucher HW, Talbot GH, Bradley JS, Edwards JE, Gilbert D, Rice LB, et al. Bad bugs, no drugs: no ESKAPE! An update from the Infectious Diseases Society of America. Clin Infect Dis Off Publ Infect Dis Soc Am. 2009 Jan 1;48(1):1-12.

[4] Spellberg B, Guidos R, Gilbert D, Bradley J, Boucher HW, Scheld WM, et al. The epidemic of antibiotic-resistant infections: a call to action for the medical community from the Infectious Diseases Society of America. Clin Infect Dis Off Publ Infect Dis Soc Am. 2008 Jan 15;46(2):155-64.

[5] Hall-Stoodley L, Costerton JW, Stoodley P. Bacterial biofilms: from the natural environment to infectious diseases. Nat Rev Microbiol. 2004 Feb;2(2):95-108.

[6] Bryers JD. Medical biofilms. Biotechnol Bioeng. 2008 May 1;100(1):1-18.

[7] Høiby N, Bjarnsholt T, Givskov M, Molin S, Ciofu O. Antibiotic resistance of bacterial biofilms. Int J Antimicrob Agents. 2010 Apr;35(4):322-32.

[8] Römling U, Balsalobre C. Biofilm infections, their resilience to therapy and innovative treatment strategies. J Intern Med. 2012 Dec;272(6):541-61.

[9] de la Fuente-Núñez C, Reffuveille F, Fernández L, Hancock REW. Bacterial biofilm development as a multicellular adaptation: antibiotic resistance and new therapeutic strategies. Curr Opin Microbiol. 2013 Oct;16(5):580-9. 
[10] Shi X, Zhu X. Biofilm formation and food safety in food industries. Trends Food Sci Technol. 2009 Sep;20(9):407-13.

[11] Gibson H, Taylor JH, Hall KE, Holah JT. Effectiveness of cleaning techniques used in the food industry in terms of the removal of bacterial biofilms. J Appl Microbiol. 1999 Jul;87(1):41-8.

[12] Otto M. Staphylococcal biofilms. Curr Top Microbiol Immunol. 2008;322:207-28.

[13] Otto M. Staphylococcal infections: mechanisms of biofilm maturation and detachment as critical determinants of pathogenicity. Annu Rev Med. 2013;64:175-88.

[14] Dunne WM. Bacterial adhesion: seen any good biofilms lately? Clin Microbiol Rev. 2002 Apr;15(2):155-66.

[15] Sousa C, Teixeira P, Oliveira R. Influence of surface properties on the adhesion of Staphylococcus epidermidis to acrylic and silicone. Int J Biomater. 2009;2009:718017.

[16] Myint AA, Lee W, Mun S, Ahn CH, Lee S, Yoon J. Influence of membrane surface properties on the behavior of initial bacterial adhesion and biofilm development onto nanofiltration membranes. Biofouling. 2010;26(3):313-21.

[17] Hamadi F, Latrache H, Mabrrouki M, Elghmari A, Outzourhit A, Ellouali M, et al. Effect of $\mathrm{pH}$ on distribution and adhesion of Staphylococcus aureus to glass. J Adhes Sci Technol. 2005 Jan 1;19(1):73-85.

[18] Pollitt EJG, Crusz SA, Diggle SP. Staphylococcus aureus forms spreading dendrites that have characteristics of active motility. Sci Rep. 2015;5:17698.

[19] Patti JM, Allen BL, McGavin MJ, Höök M. MSCRAMM-mediated adherence of microorganisms to host tissues. Annu Rev Microbiol. 1994;48:585-617.

[20] Josse J, Velard F, Gangloff SC. Staphylococcus aureus vs. Osteoblast: Relationship and Consequences in Osteomyelitis. Front Cell Infect Microbiol. 2015;5:85.

[21] Gill SR, Fouts DE, Archer GL, Mongodin EF, Deboy RT, Ravel J, et al. Insights on evolution of virulence and resistance from the complete genome analysis of an early methicillin-resistant Staphylococcus aureus strain and a biofilm-producing methicillin-resistant Staphylococcus epidermidis strain. J Bacteriol. 2005 Apr;187(7):2426-38.

[22] Navarre WW, Schneewind O. Surface proteins of gram-positive bacteria and mechanisms of their targeting to the cell wall envelope. Microbiol Mol Biol Rev MMBR. 1999 Mar;63(1):174-229.

[23] Heilmann C, Thumm G, Chhatwal GS, Hartleib J, Uekötter A, Peters G. Identification and characterization of a novel autolysin Aae with adhesive properties from Staphylococcus epidermidis. Microbiol Read Engl. 2003 Oct;149(Pt 10):2769-78.

[24] Gross M, Cramton SE, Götz F, Peschel A. Key role of teichoic acid net charge in Staphylococcus aureus colonization of artificial surfaces. Infect Immun. 2001 May;69(5):3423-6. 
[25] Cucarella C, Solano C, Valle J, Amorena B, Lasa I, Penadés JR. Bap, a Staphylococcusaureus surface protein involved in biofilm formation. J Bacteriol. 2001 May;183(9):2888-96.

[26] Schroeder K, Jularic M, Horsburgh SM, Hirschhausen N, Neumann C, Bertling A, et al. Molecular characterization of a novel Staphylococcus aureus surface protein SasC involved in cell aggregation and biofilm accumulation. PloS One. 2009;4(10):e7567.

[27] Davies DG, Parsek MR, Pearson JP, Iglewski BH, Costerton JW, Greenberg EP. The involvement of cell-to-cell signals in the development of a bacterial biofilm. Science. 1998 Apr 10;280(5361):295-8.

[28] Boles BR, Horswill AR. Agr-mediated dispersal of Staphylococcus aureus biofilms. PLoS Pathog. 2008 Apr;4(4):e1000052.

[29] Novick RP. Autoinduction and signal transduction in the regulation of staphylococcal virulence. Mol Microbiol. 2003 Jun;48(6):1429-49.

[30] Yarwood JM, Bartels DJ, Volper EM, Greenberg EP. Quorum sensing in Staphylococcus aureus biofilms. J Bacteriol. 2004 Mar;186(6):1838-50.

[31] McDougald D, Rice SA, Barraud N, Steinberg PD, Kjelleberg S. Should we stay or should we go: mechanisms and ecological consequences for biofilm dispersal. Nat Rev Microbiol. 2012 Jan;10(1):39-50.

[32] Vuong C, Saenz HL, Götz F, Otto M. Impact of the agr quorum-sensing system on adherence to polystyrene in Staphylococcus aureus. J Infect Dis. 2000 Dec;182(6):1688-93.

[33] Thurlow LR, Hanke ML, Fritz T, Angle A, Aldrich A, Williams SH, et al. Staphylococcus aureus biofilms prevent macrophage phagocytosis and attenuate inflammation in vivo. $\mathrm{J}$ Immunol Baltim Md 1950. 2011 Jun 1;186(11):6585-96.

[34] Shopsin B, Drlica-Wagner A, Mathema B, Adhikari RP, Kreiswirth BN, Novick RP. Prevalence of agr dysfunction among colonizing Staphylococcus aureus strains. J Infect Dis. 2008 Oct 15;198(8):1171-4.

[35] Lim Y, Jana M, Luong TT, Lee CY. Control of glucose- and NaCl-induced biofilm formation by rbf in Staphylococcus aureus. J Bacteriol. 2004 Feb;186(3):722-9.

[36] Le KY, Otto M. Quorum-sensing regulation in staphylococci-an overview. Front Microbiol Internet. 2015 Oct 27 cited 2016 Sep 8;6. Available from: http://www.ncbi.nlm. nih.gov/pmc/articles/PMC4621875/

[37] O'Toole G, Kaplan HB, Kolter R. Biofilm formation as microbial development. Annu Rev Microbiol. 2000;54:49-79.

[38] Costerton JW, Lewandowski Z, Caldwell DE, Korber DR, Lappin-Scott HM. Microbial biofilms. Annu Rev Microbiol. 1995;49:711-45.

[39] Mack D, Fischer W, Krokotsch A, Leopold K, Hartmann R, Egge H, et al. The intercellular adhesin involved in biofilm accumulation of Staphylococcus epidermidis is a linear beta-1,6-linked glucosaminoglycan: purification and structural analysis. J Bacteriol. 1996 Jan;178(1):175-83. 
[40] Wang X, Preston JF, Romeo T. The pgaABCD locus of Escherichia coli promotes the synthesis of a polysaccharide adhesin required for biofilm formation. J Bacteriol. 2004 May;186(9):2724-34.

[41] Kaplan JB, Ragunath C, Ramasubbu N, Fine DH. Detachment of Actinobacillus actinomycetemcomitans biofilm cells by an endogenous beta-hexosaminidase activity. J Bacteriol. 2003 Aug;185(16):4693-8.

[42] Sadovskaya I, Vinogradov E, Flahaut S, Kogan G, Jabbouri S. Extracellular carbohydrate-containing polymers of a model biofilm-producing strain, Staphylococcus epidermidis RP62A. Infect Immun. 2005 May;73(5):3007-17.

[43] Vuong C, Voyich JM, Fischer ER, Braughton KR, Whitney AR, DeLeo FR, et al. Polysaccharide intercellular adhesin PIA protects Staphylococcus epidermidis against major components of the human innate immune system. Cell Microbiol. 2004 Mar;6(3):269-75.

[44] Knobloch JK, Bartscht K, Sabottke A, Rohde H, Feucht HH, Mack D. Biofilm formation by Staphylococcus epidermidis depends on functional RsbU, an activator of the sigB operon: differential activation mechanisms due to ethanol and salt stress. J Bacteriol. 2001 Apr;183(8):2624-33.

[45] Tormo MA, Martí M, Valle J, Manna AC, Cheung AL, Lasa I, et al. SarA is an essential positive regulator of Staphylococcus epidermidis biofilm development. J Bacteriol. 2005 Apr;187(7):2348-56.

[46] Xu L, Li H, Vuong C, Vadyvaloo V, Wang J, Yao Y, et al. Role of the luxS quorum-sensing system in biofilm formation and virulence of Staphylococcus epidermidis. Infect Immun. 2006 Jan;74(1):488-96.

[47] Arciola CR, Campoccia D, Baldassarri L, Donati ME, Pirini V, Gamberini S, et al. Detection of biofilm formation in Staphylococcus epidermidis from implant infections. Comparison of a PCR-method that recognizes the presence of ica genes with two classic phenotypic methods. J Biomed Mater Res A. 2006 Feb;76(2):425-30.

[48] Corrigan RM, Rigby D, Handley P, Foster TJ. The role of Staphylococcus aureus surface protein SasG in adherence and biofilm formation. Microbiol Read Engl. 2007 Aug;153(Pt 8):2435-46.

[49] Formosa-Dague C, Speziale P, Foster TJ, Geoghegan JA, Dufrêne YF. Zinc-dependent mechanical properties of Staphylococcus aureus biofilm-forming surface protein SasG. Proc Natl Acad Sci U S A. 2016 Jan 12;113(2):410-5.

[50] Hussain M, Herrmann M, von Eiff C, Perdreau-Remington F, Peters G. A 140-kilodalton extracellular protein is essential for the accumulation of Staphylococcus epidermidis strains on surfaces. Infect Immun. 1997 Feb;65(2):519-24.

[51] Rohde H, Burandt EC, Siemssen N, Frommelt L, Burdelski C, Wurster S, et al. Polysaccharide intercellular adhesin or protein factors in biofilm accumulation of Staphylococcus epidermidis and Staphylococcus aureus isolated from prosthetic hip and knee joint infections. Biomaterials. 2007 Mar;28(9):1711-20. 
[52] Periasamy S, Joo H-S, Duong AC, Bach T-HL, Tan VY, Chatterjee SS, et al. How Staphylococcus aureus biofilms develop their characteristic structure. Proc Natl Acad Sci U S A. 2012 Jan 24;109(4):1281-6.

[53] Taglialegna A, Lasa I, Valle J. 2016. Amyloid structures as biofilm matrix scaffolds. J Bacteriol 198:2579-2588.

[54] Schwartz K, Syed AK, Stephenson RE, Rickard AH, Boles BR. Functional amyloids composed of phenol soluble modulins stabilize Staphylococcus aureus biofilms. PLoS Pathog. 2012;8(6):e1002744.

[55] Cucarella C, Tormo MA, Ubeda C, Trotonda MP, Monzón M, Peris C, et al. Role of biofilm-associated protein bap in the pathogenesis of bovine Staphylococcus aureus. Infect Immun. 2004 Apr;72(4):2177-85.

[56] Lasa I, Penadés JR. Bap: a family of surface proteins involved in biofilm formation. Res Microbiol. 2006 Mar;157(2):99-107.

[57] Latasa C, Solano C, Penadés JR, Lasa I. Biofilm-associated proteins. C R Biol. 2006 Nov;329(11):849-57.

[58] Boles BR, Thoendel M, Roth AJ, Horswill AR. Identification of genes involved in polysaccharide-independent Staphylococcus aureus biofilm formation. PloS One. 2010;5(4):e10146.

[59] Rice KC, Mann EE, Endres JL, Weiss EC, Cassat JE, Smeltzer MS, et al. The cidA murein hydrolase regulator contributes to DNA release and biofilm development in Staphylococcus aureus. Proc Natl Acad Sci U S A. 2007 May 8;104(19):8113-8.

[60] Yang S-J, Dunman PM, Projan SJ, Bayles KW. Characterization of the Staphylococcus aureus CidR regulon: elucidation of a novel role for acetoin metabolism in cell death and lysis. Mol Microbiol. 2006 Apr;60(2):458-68.

[61] Nguyen D, Joshi-Datar A, Lepine F, Bauerle E, Olakanmi O, Beer K, et al. Active starvation responses mediate antibiotic tolerance in biofilms and nutrient-limited bacteria. Science. 2011 Nov 18;334(6058):982-6.

[62] Mann EE, Rice KC, Boles BR, Endres JL, Ranjit D, Chandramohan L, et al. Modulation of eDNA release and degradation affects Staphylococcus aureus biofilm maturation. PloS One. 2009;4(6):e5822.

[63] Rani SA, Pitts B, Beyenal H, Veluchamy RA, Lewandowski Z, Davison WM, et al. Spatial patterns of DNA replication, protein synthesis, and oxygen concentration within bacterial biofilms reveal diverse physiological states. J Bacteriol. 2007 Jun;189(11):4223-33.

[64] Kaplan JB, LoVetri K, Cardona ST, Madhyastha S, Sadovskaya I, Jabbouri S, et al. Recombinant human DNase I decreases biofilm and increases antimicrobial susceptibility in staphylococci. J Antibiot Tokyo. 2012 Feb;65(2):73-7. 
[65] Kiedrowski MR, Kavanaugh JS, Malone CL, Mootz JM, Voyich JM, Smeltzer MS, et al. Nuclease modulates biofilm formation in community-associated methicillin-resistant Staphylococcus aureus. PloS One. 2011;6(11):e26714.

[66] Beenken KE, Spencer H, Griffin LM, Smeltzer MS. Impact of extracellular nuclease production on the biofilm phenotype of Staphylococcus aureus under in vitro and in vivo conditions. Infect Immun. 2012 May;80(5):1634-8.

[67] Karatan E, Watnick P. Signals, regulatory networks, and materials that build and break bacterial biofilms. Microbiol Mol Biol Rev MMBR. 2009 Jun;73(2):310-47.

[68] Beloin C, Ghigo J-M. Finding gene-expression patterns in bacterial biofilms. Trends Microbiol. 2005 Jan;13(1):16-9.

[69] Whiteley M, Bangera MG, Bumgarner RE, Parsek MR, Teitzel GM, Lory S, et al. Gene expression in Pseudomonas aeruginosa biofilms. Nature. 2001 Oct 25;413(6858):860-4.

[70] Yao Y, Sturdevant DE, Otto M. Genomewide analysis of gene expression in Staphylococcus epidermidis biofilms: insights into the pathophysiology of S. epidermidis biofilms and the role of phenol-soluble modulins in formation of biofilms. J Infect Dis. 2005 Jan 15;191(2):289-98.

[71] Pané-Farré J, Jonas B, Förstner K, Engelmann S, Hecker M. The sigmaB regulon in Staphylococcus aureus and its regulation. Int J Med Microbiol IJMM. 2006 Aug;296(4-5):237-58.

[72] Rachid S, Ohlsen K, Wallner U, Hacker J, Hecker M, Ziebuhr W. Alternative transcription factor sigmaB is involved in regulation of biofilm expression in a Staphylococcus aureus mucosal isolate. J Bacteriol. 2000 Dec;182(23):6824-6.

[73] de la Fuente-Núñez C, Reffuveille F, Haney EF, Straus SK, Hancock REW. Broad-spectrum anti-biofilm peptide that targets a cellular stress response. PLoS Pathog. 2014 May;10(5):e1004152.

[74] Regassa LB, Novick RP, Betley MJ. Glucose and nonmaintained $\mathrm{pH}$ decrease expression of the accessory gene regulator agr in Staphylococcus aureus. Infect Immun. 1992 Aug;60(8):3381-8.

[75] Regassa LB, Betley MJ. Alkaline $\mathrm{pH}$ decreases expression of the accessory gene regulator agr in Staphylococcus aureus. J Bacteriol. 1992 Aug;174(15):5095-100.

[76] Schlag S, Nerz C, Birkenstock TA, Altenberend F, Götz F. Inhibition of staphylococcal biofilm formation by nitrite. J Bacteriol. 2007 Nov;189(21):7911-9.

[77] de la Fuente-Núñez C, Reffuveille F, Fairfull-Smith KE, Hancock REW. Effect of nitroxides on swarming motility and biofilm formation, multicellular behaviors in Pseudomonas aeruginosa. Antimicrob Agents Chemother. 2013 Oct;57(10):4877-81.

[78] Cramton SE, Ulrich M, Götz F, Döring G. Anaerobic conditions induce expression of polysaccharide intercellular adhesin in Staphylococcus aureus and Staphylococcus epidermidis. Infect Immun. 2001 Jun;69(6):4079-85. 
[79] Fluckiger U, Ulrich M, Steinhuber A, Döring G, Mack D, Landmann R, et al. Biofilm formation, icaADBC transcription, and polysaccharide intercellular adhesin synthesis by staphylococci in a device-related infection model. Infect Immun. 2005 Mar;73(3):1811-9.

[80] de Nys R, Givskov M, Kumar N, Kjelleberg S, Steinberg PD. Furanones. Prog Mol Subcell Biol. 2006;42:55-86.

[81] Kuehl R, Al-Bataineh S, Gordon O, Luginbuehl R, Otto M, Textor M, et al. Furanone at subinhibitory concentrations enhances staphylococcal biofilm formation by luxS repression. Antimicrob Agents Chemother. 2009 Oct;53(10):4159-66.

[82] DeLeo FR, Diep BA, Otto M. Host Defense and Pathogenesis in Staphylococcus aureus Infections. Infect Dis Clin North Am. 2009 Mar;23(1):17-34.

[83] Günther F, Wabnitz GH, Stroh P, Prior B, Obst U, Samstag Y, et al. Host defence against Staphylococcus aureus biofilms infection: phagocytosis of biofilms by polymorphonuclear neutrophils PMN. Mol Immunol. 2009 May;46(8-9):1805-13.

[84] Guenther F, Stroh P, Wagner C, Obst U, Hänsch GM. Phagocytosis of staphylococci biofilms by polymorphonuclear neutrophils: S. aureus and S. epidermidis differ with regard to their susceptibility towards the host defense. Int J Artif Organs. 2009 Sep;32(9):565-73.

[85] Meyle E, Stroh P, Günther F, Hoppy-Tichy T, Wagner C, Hänsch GM. Destruction of bacterial biofilms by polymorphonuclear neutrophils: relative contribution of phagocytosis, DNA release, and degranulation. Int J Artif Organs. 2010 Sep;33(9):608-20.

[86] Stroh P, Günther F, Meyle E, Prior B, Wagner C, Hänsch GM. Host defence against Staphylococcus aureus biofilms by polymorphonuclear neutrophils: oxygen radical production but not phagocytosis depends on opsonisation with immunoglobulin G. Immunobiology. 2011 Mar;216(3):351-7.

[87] Flannagan RS, Heit B, Heinrichs DE. Antimicrobial mechanisms of macrophages and the immune evasion strategies of Staphylococcus aureus. Pathog Basel Switz. 2015;4(4):826-68.

[88] Scherr TD, Hanke ML, Huang O, James DBA, Horswill AR, Bayles KW, et al. Staphylococcus aureus Biofilms Induce Macrophage Dysfunction Through Leukocidin AB and Alpha-Toxin. MBio. 6(4 e01021-15)

[89] Hanke ML, Angle A, Kielian T. MyD88-dependent signaling influences fibrosis and alternative macrophage activation during Staphylococcus aureus biofilm infection. PLoS One. 2012;7(8):e42476.

[90] Hanke ML, Heim CE, Angle A, Sanderson SD, Kielian T. Targeting macrophage activation for the prevention and treatment of Staphylococcus aureus biofilm infections. J Immunol Baltim Md 1950. 2013 Mar 1;190(5):2159-68.

[91] Heim CE, Vidlak D, Scherr TD, Kozel JA, Holzapfel M, Muirhead DE, et al. Myeloidderived suppressor cells contribute to Staphylococcus aureus orthopedic biofilm infection. J Immunol Baltim Md 1950. 2014 Apr 15;192(8):3778-92. 
[92] Heim CE, Vidlak D, Scherr TD, Hartman CW, Garvin KL, Kielian T. IL-12 promotes myeloid-derived suppressor cell recruitment and bacterial persistence during Staphylococcus aureus orthopedic implant infection. J Immunol Baltim Md 1950. 2015 Apr 15;194(8):3861-72.

[93] Heim CE, Vidlak D, Kielian T. Interleukin-10 production by myeloid-derived suppressor cells contributes to bacterial persistence during Staphylococcus aureus orthopedic biofilm infection. J Leukoc Biol. 2015 Dec;98(6):1003-13.

[94] Leid JG, Shirtliff ME, Costerton JW, Stoodley P. Human leukocytes adhere to, penetrate, and respond to Staphylococcus aureus biofilms. Infect Immun. 2002 Nov;70(11):6339-45.

[95] Prabhakara R, Harro JM, Leid JG, Harris M, Shirtliff ME. Murine immune response to a chronic Staphylococcus aureus biofilm infection. Infect Immun. 2011 Apr;79(4):1789-96.

[96] Prabhakara R, Harro JM, Leid JG, Keegan AD, Prior ML, Shirtliff ME. Suppression of the inflammatory immune response prevents the development of chronic biofilm infection due to methicillin-resistant Staphylococcus aureus. Infect Immun. 2011 Dec;79(12):5010-8.

[97] Lebeaux D, Chauhan A, Rendueles O, Beloin C. From in vitro to in vivo models of bacterial biofilm-related infections. Pathogens. 2013 May 13;22:288-356.

[98] Jacqueline C, Caillon J. Impact of bacterial biofilm on the treatment of prosthetic joint infections. J Antimicrob Chemother. 2014 Sep;69(Suppl 1):i37-40.

[99] Paharik AE, Horswill AR. The Staphylococcal Bioflm: Adhesins, Regulation, and Host Response. Microbiol Spectr. 2016 Apr;4(2)

[100] McCarthy H, Rudkin JK, Black NS, Gallagher L, O'Neill E, O'Gara JP. Methicillin resistance and the biofilm phenotype in Staphylococcus aureus. Front Cell Infect Microbiol. 2015;5:1.

[101] Lister JL, Horswill AR. Staphylococcus aureus biofilms: recent developments in biofilm dispersal. Front Cell Infect Microbiol. 2014;4:178.

[102] Tasse J, Croisier D, Badel-Berchoux S, Chavanet P, Bernardi T, Provot C, et al. Preliminary results of a new antibiotic susceptibility test against bioflm installation in device-associated infections: the Antibiofilmogram ${ }^{\circledR}$. Pathog Dis. 2016 Aug;74(6). pii: ftw057.

[103] Chavant P, Gaillard-Martinie B, Talon R, Hébraud M, Bernardi T. A new device for rapid evaluation of biofilm formation potential by bacteria. J Microbiol Methods. 2007 Mar;68(3):605-12.

[104] Ceri H, Olson ME, Stremick C, Read RR, Morck D, Buret A. The calgary biofilm device: new technology for rapid determination of antibiotic susceptibilities of bacterial biofilms. J Clin Microbiol. 1999 Jun 1;37(6):1771-6.

[105] Molina-Manso D, del Prado G, Ortiz-Pérez A, Manrubia-Cobo M, Gómez-Barrena E, Cordero-Ampuero J, et al. In vitro susceptibility to antibiotics of staphylococci in biofilms isolated from orthopaedic infections. Int J Antimicrob Agents. 2013 Jun;41(6):521-3. 
[106] Revest M, Jacqueline C, Boudjemaa R, Caillon J, Le Mabecque V, Breteche A, et al. New in vitro and in vivo models to evaluate antibiotic efficacy in Staphylococcus aureus prosthetic vascular graft infection. J Antimicrob Chemother. 2016 May;71(5):1291-9.

[107] LaPlante KL, Mermel LA. In vitro activities of telavancin and vancomycin against biofilm-producing Staphylococcus aureus, S. epidermidis, and Enterococcus faecalis Strains. Antimicrob Agents Chemother. 2009 Jul;53(7):3166-9.

[108] Girard LP, Ceri H, Gibb AP, Olson M, Sepandj F. MIC versus MBEC to determine the antibiotic sensitivity of Staphylococcus aureus in peritoneal dialysis peritonitis. Perit Dial Int J Int Soc Perit Dial. 2010 Dec;30(6):652-6.

[109] Singh R, Sahore S, Kaur P, Rani A, Ray P. Penetration barrier contributes to bacterial bioflm-associated resistance against only select antibiotics, and exhibits genus-, strain- and antibiotic-specifc diferences. Pathog Dis. 2016 Aug;74(6) pii: ftw056.

[110] Siala W, Mingeot-Leclercq M-P, Tulkens PM, Hallin M, Denis O, Van Bambeke F. Comparison of the antibiotic activities of Daptomycin, Vancomycin, and the investigational Fluoroquinolone Delafloxacin against biofilms from Staphylococcus aureus clinical isolates. Antimicrob Agents Chemother. 2014 Nov;58(11):6385-97.

[111] Boudjemaa R, Briandet R, Revest M, Jacqueline C, Caillon J, Fontaine-Aupart M-P, et al. New insight into daptomycin bioavailability and localization in S. aureus biofilms by dynamic fluorescence imaging. Antimicrob Agents Chemother. 2016 Jun 13;AAC.00735-16.

[112] Saginur R, StDenis M, Ferris W, Aaron SD, Chan F, Lee C, et al. Multiple combination bactericidal testing of staphylococcal biofilms from implant-associated infections. Antimicrob Agents Chemother. 2006 Jan 1;50(1):55-61.

[113] Parra-Ruiz J, Vidaillac C, Rose WE, Rybak MJ. Activities of high-dose daptomycin, vancomycin, and moxifloxacin alone or in combination with clarithromycin or rifampin in a novel in vitro model of Staphylococcus aureus biofilm. Antimicrob Agents Chemother. 2010 Oct;54(10):4329-34.

[114] Parra-Ruiz J, Bravo-Molina A, Peña-Monje A, Hernández-Quero J. Activity of linezolid and high-dose daptomycin, alone or in combination, in an in vitro model of Staphylococcus aureus biofilm. J Antimicrob Chemother. 2012 Nov;67(11):2682-5.

[115] Luther M, LaPlante KL. Observed antagonistic effect of linezolid on daptomycin or vancomycin activity against biofilm-forming methicillin-resistant Staphylococcus aureus in an in vitro pharmacodynamic model. Antimicrob Agents Chemother. 2015 Sep 14;AAC.01604-15.

[116] LaPlante KL, Woodmansee S. Activities of daptomycin and vancomycin alone and in combination with rifampin and gentamicin against biofilm-forming methicillin-resistant Staphylococcus aureus isolates in an experimental model of endocarditis. Antimicrob Agents Chemother. 2009 Sep;53(9):3880-6. 
[117] Croes S, Beisser PS, Neef C, Bruggeman CA, Stobberingh EE. Unpredictable effects of rifampin as an adjunctive agent in elimination of rifampin-susceptible and -resistant Staphylococcus aureus strains grown in biofilms. Antimicrob Agents Chemother. 2010 Sep 1;54(9):3907-12.

[118] Saleh-Mghir A, Muller-Serieys C, Dinh A, Massias L, Crémieux A-C. Adjunctive rifampin is crucial to optimizing daptomycin efficacy against rabbit prosthetic joint infection due to methicillin-resistant Staphylococcus aureus. Antimicrob Agents Chemother. 2011 Oct 1;55(10):4589-93.

[119] Vergidis P, Rouse MS, Euba G, Karau MJ, Schmidt SM, Mandrekar JN, et al. Treatment with linezolid or vancomycin in combination with rifampin is effective in an animal model of methicillin-resistant Staphylococcus aureus foreign body osteomyelitis. Antimicrob Agents Chemother. 2011 Mar;55(3):1182-6.

[120] Jørgensen NP, Skovdal SM, Meyer RL, Dagnæs-Hansen F, Fuursted K, Petersen E. Rifampicin-containing combinations are superior to combinations of vancomycin, linezolid and daptomycin against Staphylococcus aureus biofilm infection in vivo and in vitro. Pathog Dis. 2016 Jun 1;74(4):ftw019.

[121] Bjarnsholt T, Ciofu O, Molin S, Givskov M, Høiby N. Applying insights from biofilm biology to drug development-can a new approach be developed? Nat Rev Drug Discov. 2013 Oct;12(10):791-808.

[122] Reffuveille F, Nicol M, Dé E, Thébault P. Design of an anti-adhesive surface by a pilicide strategy. Colloids Surf B Biointerfaces. 2016 Oct 1;146:895-901.

[123] Kittinger C, Marth E, Windhager R, Weinberg AM, ZarfelG, Baumert R, et al. Antimicrobial activity of gentamicin palmitate against high concentrations of Staphylococcus aureus. J Mater Sci Mater Med. 2011 Jun;22(6):1447-53.

[124] Brady RA, O'May GA, Leid JG, Prior ML, Costerton JW, Shirtliff ME. Resolution of Staphylococcus aureus biofilm infection using vaccination and antibiotic treatment. Infect Immun. 2011 Apr;79(4):1797-803.

[125] Kolodkin-Gal I, Romero D, Cao S, Clardy J, Kolter R, Losick R. D-amino acids trigger biofilm disassembly. Science. 2010 Apr 30;328(5978):627-9.

[126] Hochbaum AI, Kolodkin-Gal I, Foulston L, Kolter R, Aizenberg J, Losick R. Inhibitory effects of D-amino acids on Staphylococcus aureus biofilm development. J Bacteriol. 2011 Oct;193(20):5616-22.

[127] Lauderdale KJ, Malone CL, Boles BR, Morcuende J, Horswill AR. Biofilm dispersal of community-associated methicillin-resistant Staphylococcus aureus on orthopedic implant material. J Orthop Res Off Publ Orthop Res Soc. 2010 Jan;28(1):55-61.

[128] Giacometti A, Cirioni O, Gov Y, Ghiselli R, Del Prete MS, Mocchegiani F, et al. RNA III inhibiting peptide inhibits in vivo biofilm formation by drug-resistant Staphylococcus aureus. Antimicrob Agents Chemother. 2003 Jun;47(6):1979-83. 
[129] López D, Kolter R. Functional microdomains in bacterial membranes. Genes Dev. 2010 Sep 1;24(17):1893-902.

[130] Davies DG, Marques CNH. A fatty acid messenger is responsible for inducing dispersion in microbial biofilms. J Bacteriol. 2009 Mar;191(5):1393-403.

[131] Hughes KA, Sutherland IW, Clark J, Jones MV. Bacteriophage and associated polysaccharide depolymerases-novel tools for study of bacterial biofilms. J Appl Microbiol. 1998 Sep;85(3):583-90.

[132] Lu TK, Collins JJ. Engineered bacteriophage targeting gene networks as adjuvants for antibiotic therapy. Proc Natl Acad Sci U S A. 2009 Mar 24;106(12):4629-34.

[133] Reffuveille F, de la Fuente-Núñez C, Mansour S, Hancock REW. A broad-spectrum antibiofilm peptide enhances antibiotic action against bacterial biofilms. Antimicrob Agents Chemother. 2014 Sep;58(9):5363-71. 